Research

\title{
The role of inclusion in climate vulnerability assessment and equitable adaptation goals in small American municipalities
}

\author{
Elena Lioubimtseva ${ }^{1}$ \\ Received: 12 November 2021 / Accepted: 30 December 2021 \\ Published online: 20 January 2022 \\ (c) The Author(s) 2022 OPEN
}

\begin{abstract}
Equity and inclusion considerations are important prerequisites of effective climate adaptation planning, especially at a local scale. This study examines how climate adaptation plans of small American cities and counties consider equity in their climate vulnerability assessments and adaptation planning goals and how consideration of equity in existing adaptation plans relates to the inclusion of diverse categories of stakeholders. Data analysis is based on the content of 23 local climate adaptation plans of small urban and rural municipalities across the United States with populations of less than 300 thousand people. Correlations between conceptualization of vulnerability dimensions, inclusion of 9 categories of stakeholders, and consideration of equity in 12 different domains of climate adaptation planning are examined. The study concludes that municipalities that engage more diverse groups of stakeholders and examine the sensitivity and adaptive capacity of their populations appear to be more attentive to social equity and more likely to offer specific climate adaptation measures focusing on vulnerable groups.
\end{abstract}

Keywords Vulnerability · Exposure $\cdot$ Sensitivity · Adaptive capacity · Inclusion · Diversity · Equity · Small city · Stakeholder · Planning · United States

\section{Introduction}

Climate change adaptation planning seeks to adjust human-environmental systems in response to actual or expected climatic stimuli to minimize their harms or exploit beneficial opportunities [1]. Reducing human vulnerability to current and future climate change impacts is essential, and many cities in the United States and worldwide have developed climate adaptation plans during the past decade [2-4].

Climate adaptation planning efforts in the United States have been driven bottom-up by state, local, and tribal initiatives $[2,5]$, are developed using a wide range of methodologies, and their presence and level of coordination vary across different states [4]. Due to the absence of uniform planning guidelines and vast variety of priorities, the majority of climate adaptation plans have no clearly defined social and environmental equity standards. As a consequence, it is unclear whether the existing plans reflect the needs of all residents or only more influential groups, possibly not reducing or even disproportionally increasing the vulnerability of others [6]. It is also not known whether community members and organizations representing the interests of marginalized groups have anything to contribute to the public understanding of human vulnerability and appropriate adaptation planning targets and strategies [7].

Elena Lioubimtseva, lioubime@gvsu.edu | ${ }^{1}$ Geography and Sustainable Planning Department, Grand Valley State University, Allendale, MI 49401, USA. 
Low-income people, elderly people, infants, homeless people, displaced people, and other vulnerable populations are disproportionally affected by impacts of climate change, such as heat waves, floods, wildfires, and other hazards, vector- and water-borne diseases $[8,9]$. People of color, indigenous and immigrant communities, and other minority groups often face critical barriers to involvement in community planning due to historical disenfranchisement and have fewer resources for adaptions [10].

Scholarly literature on local climate adaptation planning is still developing, and most research has been dedicated to the experience of larger high-capacity cities $[11,12]$. Although the number of local climate adaptation plans developed by communities of all sizes and scales continues to grow in the United States in response to increasing threats of climate, very few studies have addressed the experience of small and mid-size towns and cities. Small cities, towns, and villages provide a home for a very large part of the population but have received limited attention in the climate adaptation literature, which has been largely focused on large cities. Small municipalities have fewer resources, limited opportunities for peer learning, being excluded from global and national adaptation networks [4, 13]. Because local climate adaptation planning is not mandatory in the United States, only a handful of small cities and counties have developed climate adaptation plans to date. This study examines the role of stakeholder inclusion in climate vulnerability assessment and equitable adaptation goals in small cities, towns, and counties. This inquiry is driven by the three related hypotheses:

- The consideration of equity in climate adaptation goals is related to how vulnerability is assessed by a community and whether the latter includes socioeconomic and demographic factors of sensitivity and adaptive capacity.

The scope of vulnerability assessment and the choice of its methodology is related to the inclusion of diverse groups of stakeholders involved in climate adaptation planning.

The consideration of equity in climate adaptation planning goals is related tothe inclusion of diverse groups of stakeholders involved in climate adaptation planning.

\section{Methodology}

\subsection{Local climate adaptation plans}

The dataset generated for this study consists of 23 climate adaptation plans of small urban and rural municipalities across the United States with populations of less than 300 thousand people (Table 1). The search for climate adaptation plans was informed by the Georgetown Climate Center Adaptation Clearinghouse database [14], scholarly reviews of existing local adaptation plans [2,5] 2016; [3, 15], and [16], Internet searches, and information requests to the jurisdictions identified through the searches. From the pool of 482 documents, initially found through the searches, only 23 municipalities with populations less than 300 thousand people with publicly available local climate adaptation plans have been identified across the country. These cities, towns, and counties are listed in Table 1, with a summary of climate change impacts addressed in their climate adaptation plans. Our sample of 23 plans is certainly not exhaustive. Other plans of small cities exist and address adaptation planning under various titles, not including the term "adaptation" in their titles, such as "resilience plan", "climate action plan", "hazards mitigation plan", "climate smart plan", "climate sustainability plan", "healthy climate plan", "community heat relief plan", etc. They were not included in this analysis to avoid potential terminological ambiguities.

\subsection{Analytical framework}

This study is exploring complex relationships among the three aspects of climate adaptation planning: (a) vulnerability assessment scope, (b) inclusion of stakeholders in climate adaptation planning, and (c) consideration of equity in adaptation planning goals in various domains (Fig. 1). 
Table 1 Local climate adaptation plans examined in this study

\begin{tabular}{|c|c|c|c|c|c|c|c|c|c|}
\hline \multirow[t]{2}{*}{ Municipality } & \multirow[t]{2}{*}{ Source } & \multicolumn{8}{|c|}{ Impacts of climate change addressed } \\
\hline & & $\begin{array}{l}\text { Shoreline } \\
\text { changes }\end{array}$ & Severe storms & Extreme heat & Extreme cold & Flooding & Drought & Wildfires & Seasonal shifts \\
\hline Albany, NY & {$[65]$} & & $x$ & $x$ & $x$ & $x$ & & & $x$ \\
\hline Alger County, MI & {$[68]$} & $X$ & $x$ & $x$ & $x$ & $x$ & $\mathrm{X}$ & $\mathrm{X}$ & $x$ \\
\hline Boulder County, CO & [69] & & & $x$ & $x$ & $x$ & $x$ & $x$ & \\
\hline Chula Vista, CA & {$[70]$} & $\mathrm{X}$ & $\mathrm{X}$ & $x$ & & $x$ & $x$ & $\mathrm{X}$ & \\
\hline Corte Madera, CA & [63] & $\mathrm{X}$ & $x$ & $\mathrm{X}$ & & $\mathrm{x}$ & $x$ & $\mathrm{X}$ & \\
\hline Flagstaff, AZ & {$[71] ;[72]$} & & $x$ & $x$ & & $x$ & $x$ & $\mathrm{X}$ & $x$ \\
\hline Georgetown, ME & {$[66]$} & $X$ & $x$ & & & $x$ & & & \\
\hline Groton, CT & [73] & $x$ & $x$ & $\mathrm{X}$ & & $x$ & $\mathrm{X}$ & & $x$ \\
\hline lowa City, IA & {$[74]$} & & $x$ & $\mathrm{x}$ & & $x$ & $x$ & & $x$ \\
\hline Keene, NH & {$[75,76]$} & & $x$ & $x$ & $x$ & $x$ & $x$ & & $x$ \\
\hline Laguna Woods, CA & {$[61]$} & & $x$ & $x$ & & $x$ & $x$ & $x$ & \\
\hline Marquette, MI & {$[52]$} & $X$ & $x$ & $x$ & & $x$ & $x$ & & $x$ \\
\hline Marquette County, MI & {$[53]$} & $x$ & $x$ & $x$ & $x$ & $x$ & $x$ & $\mathrm{X}$ & $x$ \\
\hline Marshfield, MA & [77] & $x$ & $x$ & $x$ & $x$ & $x$ & & & $x$ \\
\hline North Kingston, RI & {$[78]$} & $\mathrm{X}$ & $x$ & $x$ & $x$ & $x$ & & & $\mathrm{x}$ \\
\hline Punta Gorda, FL & {$[79,80]$} & $X$ & $x$ & $x$ & & $x$ & & & \\
\hline Salem, MA & [81] & $x$ & $x$ & $x$ & & $x$ & & & \\
\hline Santa Cruz, CA & {$[62,82]$} & $x$ & $x$ & $x$ & & $x$ & $\mathrm{X}$ & $\mathrm{X}$ & \\
\hline Sarasota, FL & {$[83,84]$} & $x$ & $x$ & $x$ & & $x$ & & & \\
\hline Taos County, NM & {$[85]$} & & $\mathrm{x}$ & $x$ & & $x$ & $x$ & $X$ & $x$ \\
\hline Tompkins County, NY & {$[86]$} & & $x$ & $x$ & & $x$ & $x$ & & \\
\hline Tybee Island, GA & {$[67]$} & $x$ & $x$ & & & $x$ & & & \\
\hline Watsonville, CA & {$[64]$} & $x$ & $X$ & $X$ & & $x$ & $X$ & $X$ & \\
\hline
\end{tabular}

Fig. 1 Conceptual framework for the analysis of climate adaptation plans (adapted from [51])

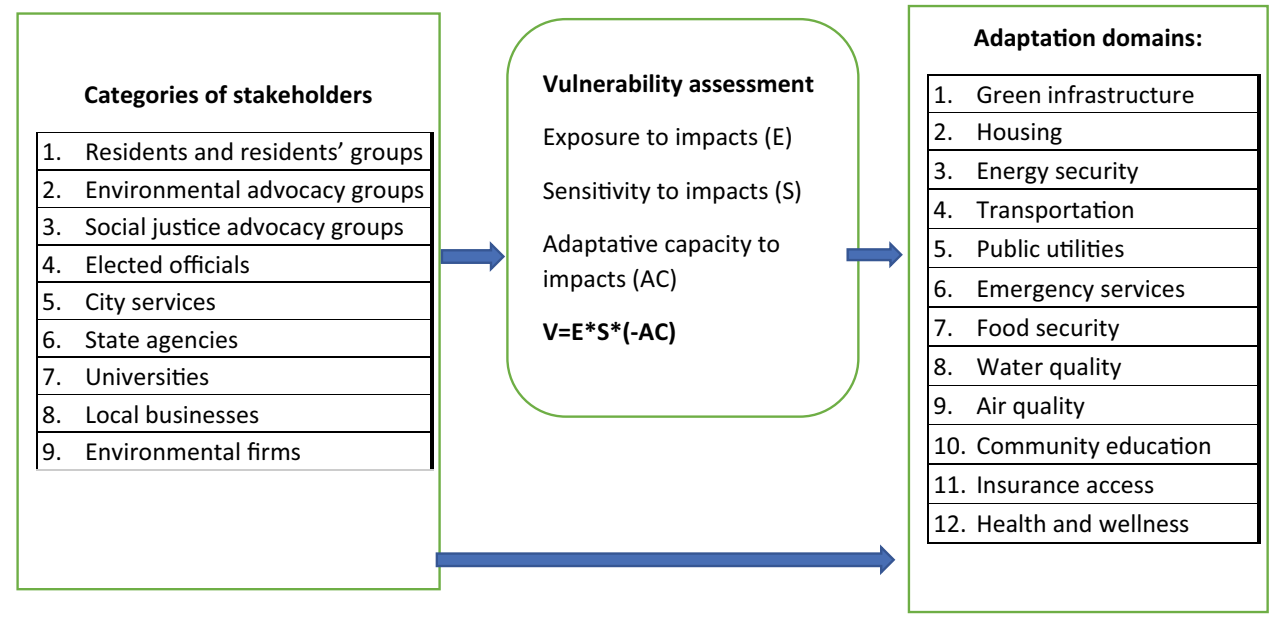

\subsubsection{Interpretation of vulnerability}

The IPCC Assessment Report Five (AR5) [1] defined vulnerability to climate change impacts as"the propensity or predisposition to be adversely affected by impacts of climate change" In the earlier literature, including the IPCC AR4 [17], this concept was defined as "the degree to which a system is susceptible to, or unable to cope with adverse effects of climate change, including climate variability and extremes". In this older conceptual framework vulnerability was considered as "a function of the character, magnitude, and rate of climate change and variation to which a system is exposed, its sensitivity, 
and its adaptive capacity" [17], while under the IPCC AR5 framework, sensitivity and adaptive capacity are considered internal parts of vulnerability, as opposed to exposure, conceptualized as an external factor $[1,18]$. This paradigm shift reflects the reconceptualization of vulnerability as a socioeconomic variable. In practice, however, both frameworks have been operationalized by various agencies $[18,19]$ and many local and regional climate adaptation studies continue to adhere to the IPCC AR4 definition of vulnerability [20-22]. In place-based community-scale assessments [23-25] vulnerability is most commonly conceptualized as a composite variable defined by both biophysical and socioeconomic factors of exposure, sensitivity and adaptive capacity based on Vulnerability Scoping Diagram (VSD) approach [26-28] as a combination of geographical, demographic, and socioeconomic indicators (Table 2).

The IPCC defined exposure as "the nature and degree to which a system is exposed to significant climate variations" in AR4 [17] and as 'the presence of people, livelihoods, species or ecosystems, environmental functions, services, and resources, infrastructure, or economic, social, or cultural assets in places and settings that could be adversely affected" in the AR5 [1], further emphasizing its place-based spatial nature. Exposure may be also represented as changes in longterm climate conditions or by changes in climate variability, including the magnitude and frequency of extreme events [29]. Defined by geography, its spatial pattern is uneven, even at a scale of smaller municipalities. Some areas are more exposed than others to effects of flooding, wildfires, heat waves, and storms due to their landforms, soils, vegetation, hydrology, population density, and other elements of their physical and cultural landscape. Regardless of being considered as an internal or external factor of cities' vulnerability to climate change, analysis of exposure to specific impacts provides crucial information for climate adaptation planning $[18,21]$.

Sensitivity is the degree to which a system may be affected, either adversely or beneficially, when exposed to climate variability or change or geophysical hazards [1]. For example, the sensitivity to the effects of flooding, wildfires and heat waves of people living in the same place varies significantly depending on their age, gender, health, and wellness. Elderly people, pregnant women, infants, and people with health conditions and physical or mental disabilities are particularly sensitive to weather extremes.

Adaptive capacity relates to the capacity of systems, institutions, humans, and other organisms to adjust to potential damage, to take advantage of opportunities, or to respond to consequences [1]. At the local scale, it implies all community and individuals' assets available for climate adaptation, such as infrastructure, financial assets, access to infrastructure, information, technology, transportation, insurance, health care, food, and other resources. For example, consequences of exposure to the same disaster, such as a hurricane or a wildfire, depend on the effectiveness of adaptation and emergency plans, evacuation and rescue operations, and the ability of communities or individuals to safely relocate and restore their livelihoods. Adaptation capacity is the key factor defining adaptation planning options.

In this study, vulnerability is understood as a function of exposure, sensitivity and adaptive capacity: $V=f\left[E * S^{*}\right.$ $(-A C)]$, where $V$ is vulnerability, $E$ is exposure, $S$ is sensitivity, and $A C$ is adaptive capacity In theory, if all factors are considered, human vulnerability is an objective measurable variable used to inform climate adaptation goals. Communities are encouraged to conduct their vulnerability assessment before embarking on climate adaptation planning projects [30-32], and the majority of local adaptation plans are either based on a vulnerability assessment report or include at least a section dedicated to the discussion of vulnerability. In the absence of national and state guidelines, cities are left to almost endless choice of methodologies for vulnerability assessment, ranging from community surveys to modeling scenarios developed by external firms or local universities, who also use a wide range of conceptual frameworks [4, 15]. Vulnerability assessments provide critically important information for guiding climate adaptation goals and future performance evaluations of climate adaptation plans. In theory, they are meant to be objective. We argue, however, that in practice, local vulnerability assessments are highly subjective because they depend on how they are conducted, by whom, and with whose priorities in mind. This is why we prefer to use the term "perceived vulnerability" (PV), commonly used in social and clinical psychology $[33,34]$ as a measure of subjective perception of vulnerability by groups of population. In health behavior theories PV reflects a belief about the likelihood of a health threat's occurrence or the likelihood of developing a health problem (e.g. cancer) or being exposed to infections (e.g. HIV) or natural disasters [34, 35]. We find this concept especially relevant for describing believes of various stakeholders about the likelihoods of their communities being exposed to impacts of climate change.

\subsubsection{Consideration of climate equity and justice}

Issues of climate equity and justice are still far more readily discussed in the scholarly literature at a country-to-country scale than at a scale of individual cities $[7,10,36]$ and hardly any systematic data are available on climate equity in small municipalities [16]. Equity can be defined as "the state, quality or ideal of being just, impartial and fair" (AECF, 2021). In 


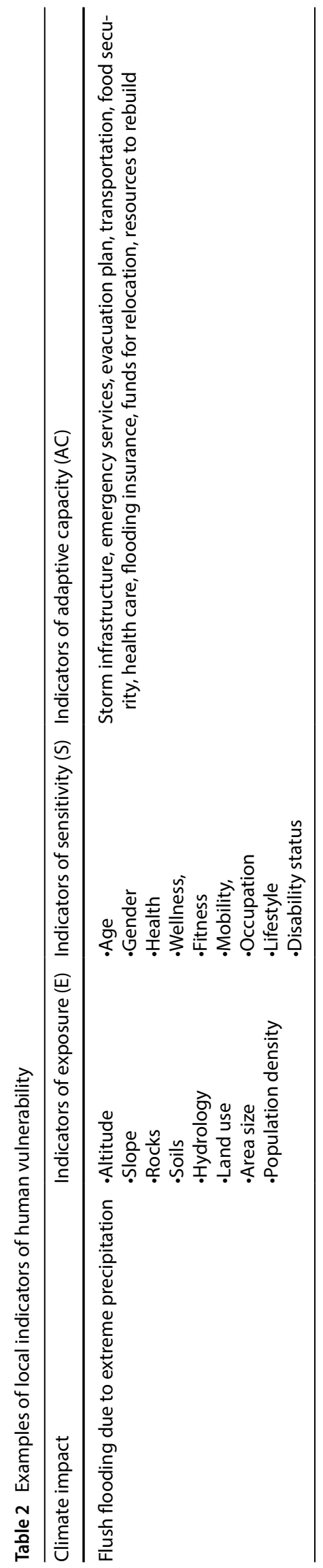


the context of this study, it is examined both as a process and its outcomes that relate to the consideration of climate vulnerabilities and adaptation objectives. Equity is a social concept closely related to the legal term "justice". Climate justice offers a human rights perspective on the climate crisis, acknowledging that climate change has differing social, economic, public health, and other adverse impacts on the underprivileged population [37]. Climate justice can have distributive and procedural forms [38], where the former relates to the distribution of adverse impacts of climate change and the latter to how and by whom adaptation planning decisions should be made [7]. In climate adaptation planning, equity and justice imply planning strategies to eliminate disparities and create physical and social environments that aim to ensure a fairer distribution of community resources along race, class, gender, and other dimensions of diversity [39]. Climate change adaptation planning seeks to adjust human-environmental systems in response to actual or expected climatic stimuli to minimize their harms or exploit beneficial opportunities. Therefore, attention to equity and justice in climate adaptation planning is paramount to reduce the vulnerability of all residents and neighborhoods. In this study, we use twelve (12) domains of climate adaptation planning to assess "consideration of equity" (CE) in climate adaptation plans. These twelve adaptation domains include green and blue infrastructure, housing, energy security, transportation infrastructure and services, utility infrastructure and services, emergency services, food security, water quality, air quality, community education, insurance access, and health and wellness. Consideration of equity in each of these 12 domains is evaluated on a scale from 0 to 3, defined as follows: 0 -adaptation domain is absent; 1 -adaptation domain is present, but does not address equity; 2-adaptation domain is present and equity is acknowledged as a value but strategies for achieving equity are not explained; 3 -adaptation domain is present and strategies for achieving equity are explained.

\subsubsection{Diversity and inclusion of stakeholders}

Diversity involves various social categories based on class, gender, occupation, income, education, race, ethnicity, age, and ability, which may have very different levels of exposure, sensitivity, and adaptive capacity to climate impacts. Observable dimensions of diversity include characteristics such as gender, race, ethnicity, and age, which are legally protected from discrimination in the United States [40] but can also include many other characteristics, such as education, professional and socioeconomic background, immigration status, income, and various cultural associations (e.g., religion, ancestry, or social causes). Low-income people and minorities often tend to live in more hazard-prone and crowded areas with older infrastructure [41], higher air and water pollution [42], and limited access to green spaces [43]. These circumstances increase their vulnerability to impacts of climate change and reduce their capacity to adapt to and withstand extreme events [9]. The concept of diversity is closely related to inclusion, which can be defined as the degree to which an individual perceives that he or she is an esteemed member of a group through experiencing treatment that satisfies his or her needs for belongingness and uniqueness [44]. To serve the entire community, the process of developing a local adaptation plan must be inclusive [45]; engaging the entire spectrum of stakeholders and especially vulnerable groups is a criterion of procedural justice [46]. While it is difficult to capture all demographic and socioeconomic data necessary to fully evaluate the diversity and inclusion of stakeholders, the involvement of civil rights and urban advocacy organizations, such as the National Urban League; climate justice groups, such as the Climate Collaborative, Climate Justice Alliance, and Earth Justice; and local community organizations advocating for climate equity and justice, can provide at least indirect insights about social inclusion.

In this study, we examine nine (9) categories of stakeholders involved in the design of local climate adaptation plans: residents and neighborhood associations, environmental and climate advocacy groups, social justice advocacy groups, elected members of local governments, planning departments and public utilities staff, representatives of state or federal agencies, academics, local businesses, and external environmental engineering firms hired by cities to assist with vulnerability assessment and plan writing. Their participation in climate adaptation planning is used here as a proxy measure of "inclusion of stakeholders" (IS). Stakeholders' engagement in adaptation planning is classified on a scale from 0 to 3: none (0), participant (1), partner (2), and coauthor (3), ranging from no influence to total influence, as a simplified application of the "inform—consult—collaborate—empower" model [47].

\subsection{Assessment}

All 23 adaptation plans are evaluated and compared based on criteria of their perceived vulnerability (PV), inclusion of stakeholders (IS) in the adaptation planning process, and consideration of equity (CE) in the proposed climate adaptation goals. The criteria for PV, IS, and CE ranking are summarized in Table 3. These criteria are not weighted, assuming that they are equally important, which is a methodological limitation of this pilot study. 


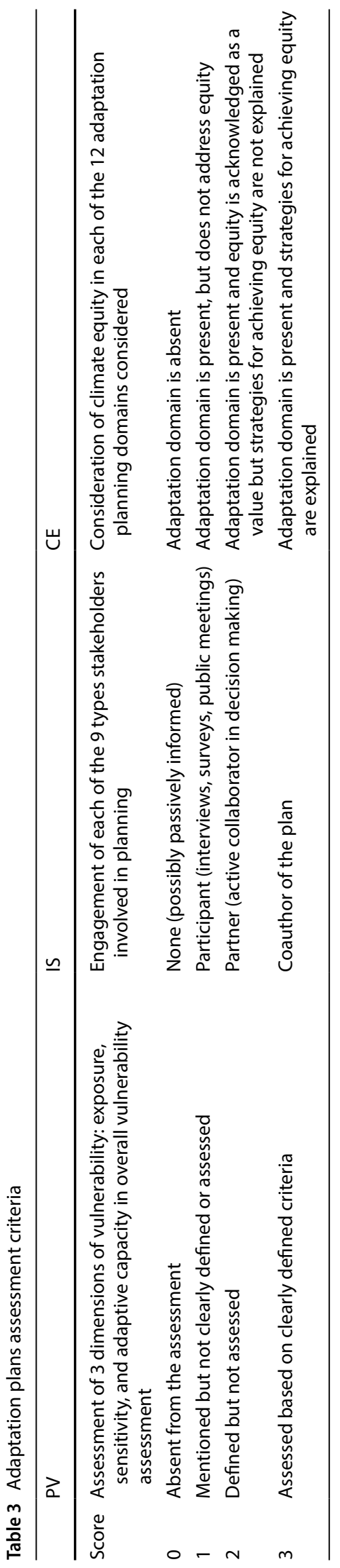


To examine how these three variables correlate and influence each other, I evaluated them based on the content of each adaptation plan in this sample.

$\mathrm{PV}=\frac{\mathrm{E}+\mathrm{S}+\mathrm{AC}}{9} \times 100 \%$, where $\mathrm{E}$ is exposure, $\mathrm{S}$ is sensitivity, and $\mathrm{AC}$ is adaptive capacity, each ranked on a scale from 0 to 3 based on the level of their assessments in the local adaptation plans.

IS $=\Sigma(\mathrm{s} 1,2,3 \ldots 0.9) / 27 \times 100 \%$, where " $\mathrm{s}$ " is a number of categories of stakeholders involved, ranging from 1 to 9 categories, and their engagement ranked on a scale $0-3$.

$\mathrm{CE}=\Sigma(\mathrm{ad} 1,2.0 .12) / 36 \times 100 \%$, where "ad" is a number of possible adaptation planning domains in each plan, ranging from 1 to 12, with consideration of equity in each ranked on a scale from 0 to 3 .

\section{Results and discussion}

Figures 2, 3, 4 and 5 illustrate patterns of relationships among perceived vulnerability, inclusion of stakeholders, and consideration of equity. First, it is clear that communities' PV varies significantly, and the magnitude of this variability is driven by the choice methodological guidelines and assessment approaches. This is because some municipalities choose to interpret vulnerability solely as biophysical exposure to impacts, while others also consider socioeconomic aspects of sensitivity and adaptive capacity. Vulnerability assessment is an essential prerequisite of adaptation planning $[1,30$, 32 ] and is typically encouraged in the guidelines of various state, national, and international agencies [31, 48-50]. In the absence of national climate adaptation standards and state guidelines in most states, local communities define and assess their vulnerability in a variety of ways. This makes the tasks of long-term monitoring and comparative analysis very problematic. As Woodruff and Stults [3] show, there are "numerous strategies but limited implementation guidance in local climate adaptation plans". In our sample, all 23 plans provided analysis of exposure to current and expected climate impacts, and 17 of them received the highest score (3) for providing detailed analysis based on their location and physiographic conditions. However, only 4 plans received the top score (3) for their sensitivity assessments, while 10 plans did not mention any sensitivity criteria at all. Only 5 plans scored 3 based on their adaptive capacity assessments, and 7 plans omitted consideration of adaptive capacity criteria together. Such omission of socioeconomic dimensions of vulnerability is neither unique to small cities nor to the United States and has been previously noted in other comparative adaptation studies $[6,51]$. Local plans use a very wide range of methodological and conceptual approaches, largely differing from

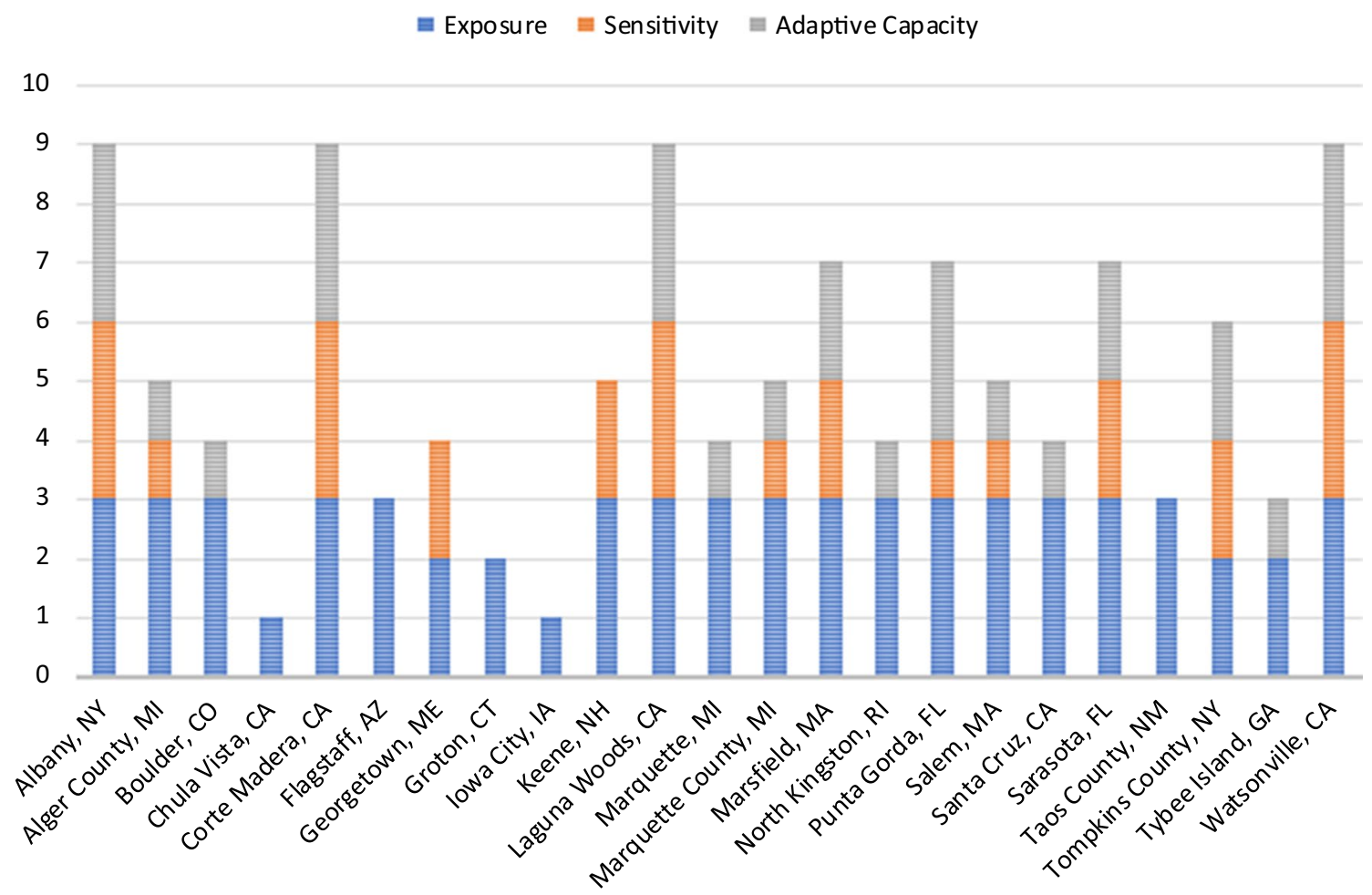

Fig. 2 Assessment of exposure, sensitivity, and adaptive capacity considered in the local plans 
Inclusion of stakeholders

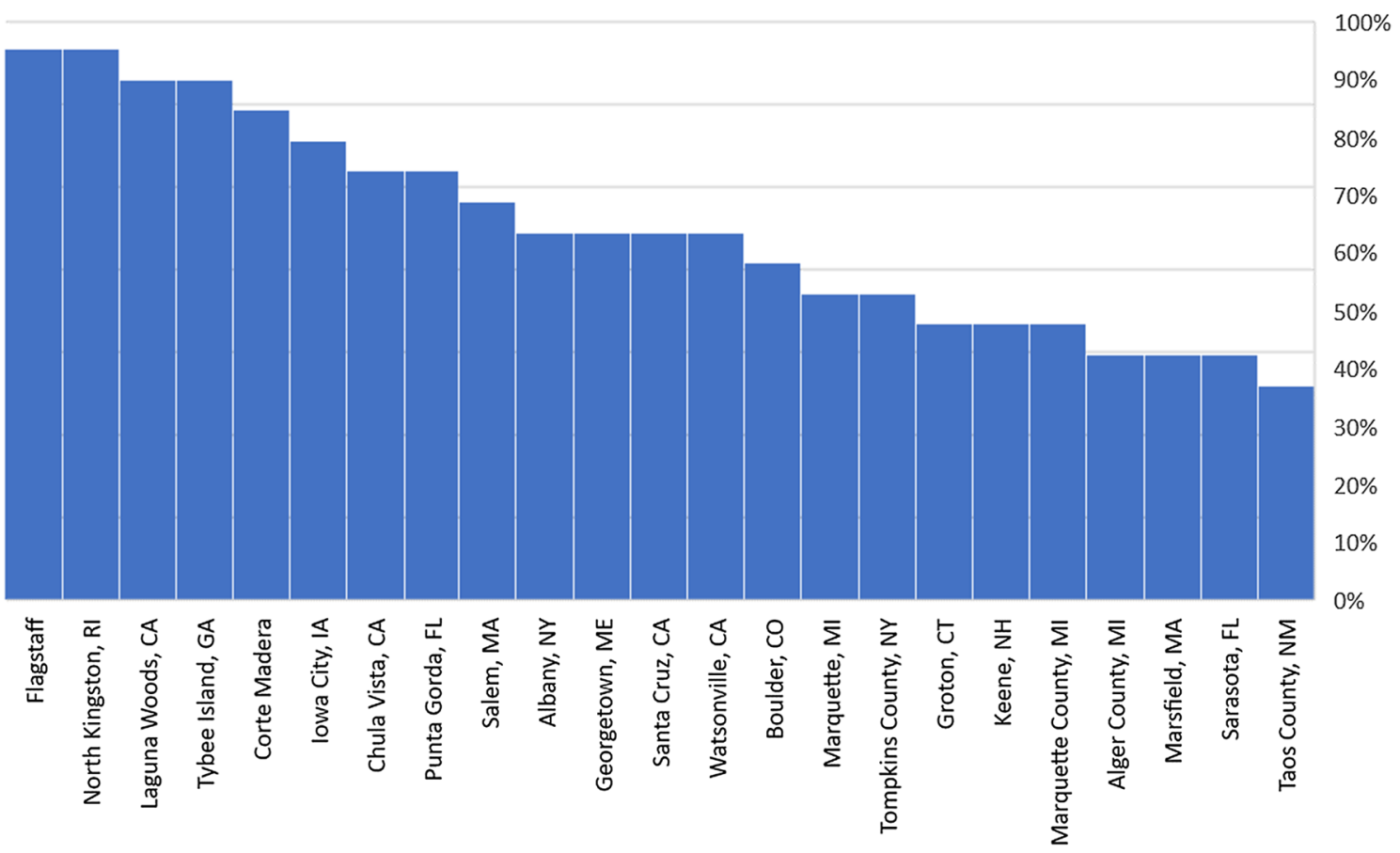

Fig. 3 Inclusion of stakeholder categories in the development of climate adaptation plans

state to state and city to city, and their interpretations of what "vulnerability" is and how it can be assessed are far from uniform. Perhaps the most striking example of such a variety of approaches in this sample is offered by the plans of the City of Marquette [52] and Marquette County [53] in Michigan. Both plans are published the same year, covering overlapping geographic areas (the City of Marquette and the surrounding predominantly rural area of Marquette County, which also includes the City of Marquette). However, being developed by different groups of stakeholders with the assistance of different external agencies, they adopted different methodological approaches, not aiming for compatibility or coordination. Overall, attention to physical exposure to climate impacts clearly prevails over socioeconomic aspects of sensitivity and adaptive capacity in the majority of climate adaptation plans under various assessment guidelines (Fig. 2). In other words, climate adaptation is still seen by some communities as a synonym of hazard mitigation.

Similarly, the inclusion of stakeholders varies significantly among the plans (Fig. 3). While local governments, planning departments, and other municipal services typically coauthor most plans, the engagement of residents, social and environmental advocacy groups, local businesses, and academia varies significantly from place to place. Such variability of participants could be the main reason for a very broad range of guidelines adopted by individual communities. For example, university cities benefit from the involvement of local faculty and students. They are far more likely to use planning guidelines that are well informed by robust climate data and current scholarly literature and to invite climate adaptation experts to public meetings. Collaboration with local universities promotes the national and international visibility of small college towns and often brings external grants to fund vulnerability assessments and climate adaptation plans, sometimes used as case studies in larger methodological projects.

In regard to equity in climate adaptation domains, the differences among the plans appear to be striking, with the CE index ranging from $87 \%$ for Albany, NY to $11 \%$ for Georgetown, ME (Fig. 4).

Pearson correlation coefficient $\underline{r}$ was used to explore the relationships between PV, IS, and CE to test the initial hypotheses (p. 3). There is a significant positive correlation $(r=+0.57)$ between $\mathrm{PV}$ and $\mathrm{CE}$, suggesting that when vulnerability assessment includes not only biophysical but also socioeconomic and demographic factors, it is more conducive to consideration of equity in adaptation planning goals. A moderate positive correlation $(r=+0.40)$ also appears between IS and CE, signaling that plans developed by more inclusive groups of diverse stakeholders are more likely to pay attention to equity in their climate adaptation goals. These findings agree with other studies on the role of stakeholder engagement and public participation in successful climate adaptation planning [54-57]. These correlations are not direct causations and may be explained by several factors calling for further in-depth research. 
Consideration of equity

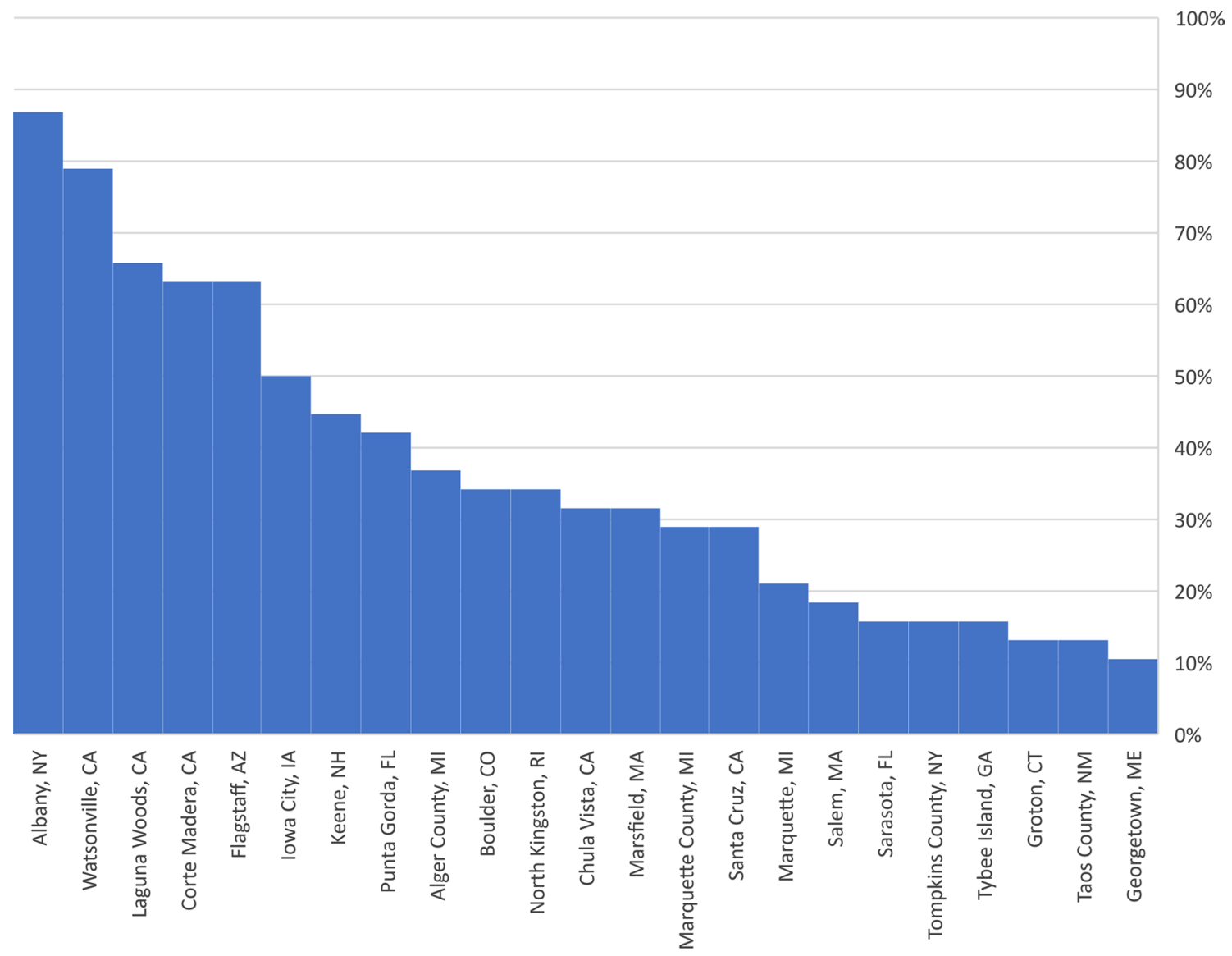

Fig. 4 Consideration of equity in climate adaptation domains

For example, it is possible that more progressive cities and cities with demographically diverse populations, such as Albany, NY and Watsonville, CA, make more intentional efforts to address diversity, equity, and inclusion in city planning. The recency of the plan appear to be another significant factor-with a few exceptions, climate adaptation plans produced during the past 5-6 years tend to include more diverse stakeholders, pay more attention to socioeconomic aspects of vulnerability in addition to exposure and provide more information about equity in their adaptation goals (Fig. 5). These are positive signs, suggesting that cities learn from the evolving body of knowledge and improve their methodologies over time.

On the other hand, only a negligible correlation was found between IS and PV. This finding agrees with a recent crossnational comparative study by Lioubimtseva and da Cunha [51] of French and American climate plans, suggesting that in practice, stakeholders have little to contribute to the choice of vulnerability assessment methods. Guidelines and protocols for vulnerability assessments are typically written by experts and are often packaged with funding sources or training programs of their sponsoring agencies, leaving little room for change. The importance of coordinated methodologies can be further illustrated by a handful of plans from the state of California. California provides significant assistance, coordination, and technical guidelines to local governments through a state-wide climate adaptation strategy and adaptation planning guides [58]. The state addressed adaptation to climate change through the California Climate Adaptation Strategy [58] and California Adaptation Planning Guide [48], providing a state-wide decision-making framework intended for use by local and regional stakeholders. The state also produced four major assessments of local and statewide vulnerabilities to climate change in 2006, 2009, 2012, and 2018 [59] and developed Cal-Adapt [60]—a web-based platform, which enables city and county planners, government agencies, and the public to identify potential climate change risks in specific areas throughout California. Benefiting from the state climate policies, Californian cities are by far ahead of the rest of the nation in terms of both the quantity and quality of local adaptation plans. The state fosters many opportunities for collaboration and peer learning through state-wide networks and platforms, such as Cal-Adapt and 


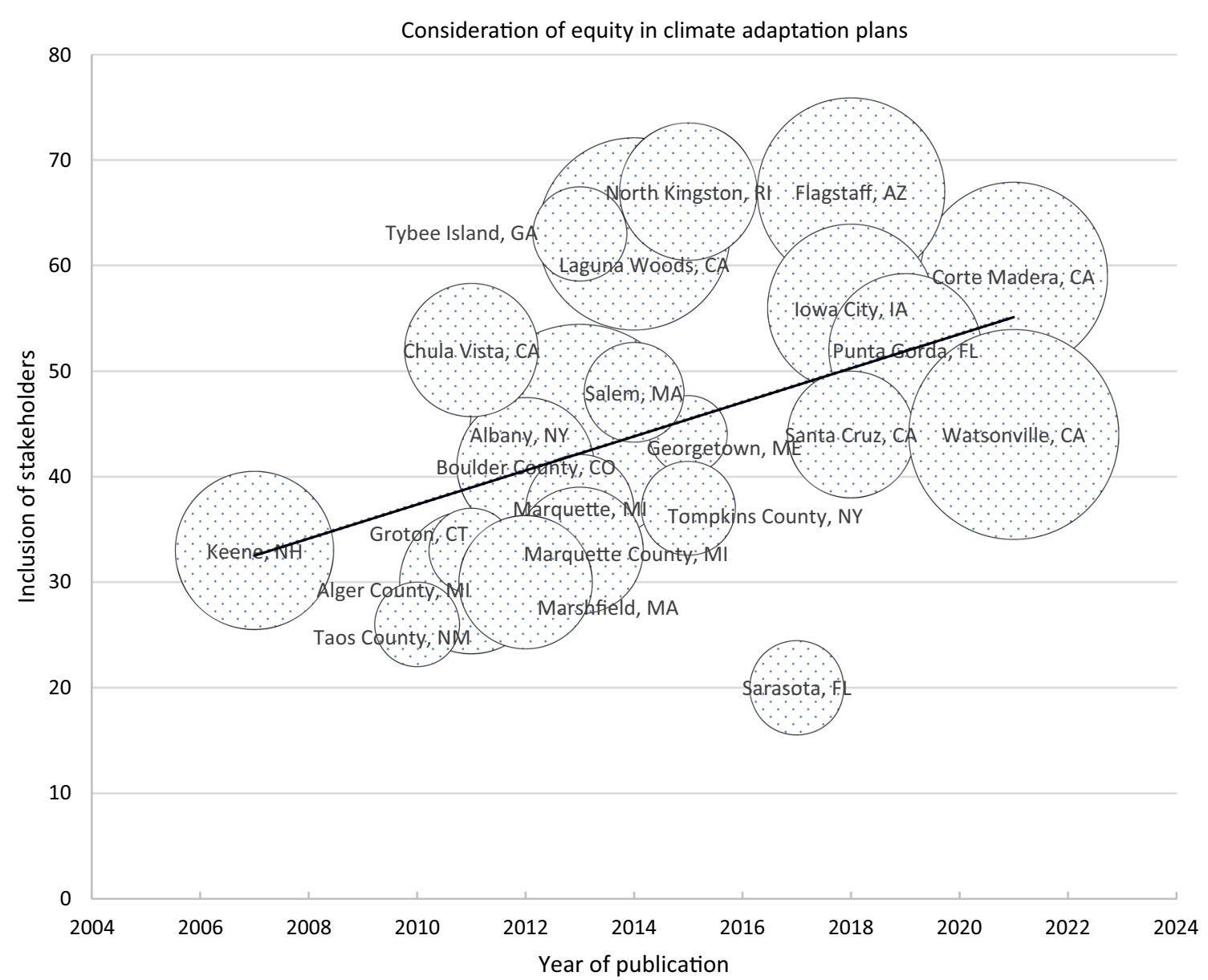

Fig. 5 Consideration of equity in climate adaptation plans and inclusion of stakeholders changing with time (bubble size represents CE)

the ILG [49], leading to more coordinated planning efforts. As a result, plans of Californian cities use comparable metrics, data, and tools and demonstrate awareness of climate adaptation plans of other municipalities across the state [61-64].

Interpretation of these preliminary findings requires deeper analysis of cultural, environmental, demographic, social, and economic factors. Many small municipalities have distinctive and sometimes overlapping niche functions, such as coastal vacation towns (Punta Gorda, FL, Sarasota, FL, Santa Cruz, CA, Salem, MA, Marshfield, MA, Tybee Island, GA, North Kingston, Rl, Georgetown, ME), popular active lifestyle and arts destinations (Boulder, CO, Flagstaff, AZ, Taos, NM), retirement communities (Laguna Woods, CA, Corte Madera, CA, Sarasota, FL, Punta Gorda, FL, Flagstaff, AZ), college towns (Santa Cruz, CA, Marquette, lowa City, Thompkins County, Boulder, CO, Albany, NY), etc. Many of these small cities have a great reputation of exceptional quality of life (Boulder, CO, Santa Cruz, CA, Watsonville, CA, Flagstaff, AZ), and some are among the most expensive places to live, with their median household income and house value significantly higher than the state and national averages. Although some of these cities are relatively wealthy, they harbor distinctive pockets of extremely vulnerable populations and sharp socioeconomic contrasts. Compared to large cities, they have more distinctive vulnerable groups. For example, cities with high rates of populations living below the poverty line, such as Albany and Santa Cruz, articulate concerns about low-income residents in their plans [62,65]. Communities with large retired populations, such as Laguna Woods, CA [61] and Corte Madera, CA [63], are especially concerned with sensitivities of the elderly and people with limited mobility as well as other vulnerable groups, e.g., people working outdoors in farming communities. Small island communities, such as Georgetown, ME and Tybee Island, GA are already under extremely high stress due to sea-level rise and are particularly concerned with the vulnerability of coastal infrastructure and seasonal population migration $[66,67]$. More effective articulation of specific goals relevant for each community would be possible only with deeper analysis of their unique vulnerability profiles, truly inclusive of all groups of stakeholders. This would require the development of comprehensive state-wide and national standards for climate adaptation planning, creating policies to encourage climate adaptation planning nationwide, and providing adequate resources for local governments. 
This research is still at its early stage and has several limitations. Due to the small size of our sample, this semiquantitative analysis should be regarded with caution and not be used for extrapolation. Twenty-three plans discussed here are climate adaptation champions and are not representative of the state of adaptation planning in other small cities and counties in the United States. Many of these communities, but not all, tend to have more abundant financial and intellectual resources and more progressive agendas, benefiting from collaboration with local universities and long histories of civic engagement. Factors such as population age, income, occupation, ethnic and racial diversity, education attainment, and political orientation do influence adaptation priorities, and their in-depth quantitative analysis could provide more insights. However, the number of small municipalities with adaptation plans is still too limited to generate a sufficiently robust statistical pool to explore the role of these factors. The information examined here is derived from the climate adaptation plans and auxiliary documents and might be missing many nuances that could be captured through direct observations of the planning process, resident surveys and interviews. More detailed field research and long-term monitoring of participatory planning and plan implementation are necessary to gain more complete information. Despite these limitations, this research is among the very first studies to offer conceptual and methodological framework to examine relationships between vulnerability, inclusion, and consideration of equity in adaptation planning strategies. It offers important insights and data, setting a foundation for future national and international assessments of local climate adaptation plans.

\section{Conclusions}

Climate adaptation planning is still an emerging planning field, and its importance is likely to increase in future years as our society is experiencing an increasing number of effects of climate change. Urban poor, people of color, immigrants, and other marginalized populations are disproportionally affected by impacts of climate change and extreme events already, and their vulnerability is likely to increase unless equitable adaptation measures are put in place by municipalities. This study breaks new ground in methods and their application to assess equity in climate plans and is among the first systematic studies exploring connections between diversity, equity, and inclusion in climate adaptation planning at a local scale. In the absence of national climate adaptation policies, the majority of cities, towns, and counties in the United States still have no climate adaptation plans. Even large high-impact cities use numerous strategies with no implementation guidelines to assure their compatibility for long-term monitoring and coordination [3], but this is especially challenging for smaller municipalities, which lack adequate resources, guidance, and motivation [4]. The handful of local adaptation plans of small municipalities examined in this study are pioneers providing useful lessons to the rest of the country.

State climate adaptation policies, such as in California, are still rarely available but would be crucial in supporting local adaptation planning efforts nationwide, as is support from academia. However, according to the GCC AC portal (2021), only 17 states have finalized their state-led climate adaptation plans, and 5 others have other adaptation planning activities on the way, with 28 other states remaining inactive in this area. As a result, the share of cities with climate adaptation plans in the U.S. is still substantially lower than that in many other developed countries, e.g., the United Kingdom, European Union members, Australia, and New Zealand. There is a clear urgent need for nationwide climate adaptation policies, guidelines, standards, and incentives for state and local governments to get on board.

Two of our three hypotheses have proven to be true and one false. We found no correlation between the inclusion of stakeholders and consideration of sensitivity and adaptive capacity in vulnerability assessment. Vulnerability assessment is a technical process and involves the analysis of climate change trends and scenarios and environmental, social, and economic data. While a variety of methodological guidelines are available to local governments [14, 31, 50, 58], few participants, even if invited, can competently contribute to assessment protocols due to their technical complexity. As a result, many municipalities delegate vulnerability assessments to external experts, such as private firms or university partners. Even with broad coalitions of stakeholders being involved in designing local climate adaptation plans, the conceptual framework and metrics of vulnerability and its indicators are decided by a small number of experts, and the odds of community involvement in the choice of guidelines are very low.

However, this data analysis reveals a very significant correlation between the inclusion of diverse stakeholders and higher considerations of equity in climate adaptation plans. An even stronger correlation is apparent between the consideration of socioeconomic dimensions of a community's perceived vulnerability, such as sensitivity and adaptive capacity, and consideration of equity in the proposed adaptation strategies in the plans. Municipalities that examine their vulnerability beyond physical exposure to climate impacts and consider the demographic, social, and economic 
characteristics of their populations appear to be much more attentive to social equity and offer specific measures focusing on vulnerable groups. This finding is important and should be further examined as a potentially crucial prerequisite for equitable adaptation planning. All underlying factors of this relationship are not fully explained but have been noted in other city-scale studies [51,54]. Do communities equipped with a more complete understanding of vulnerability pay more attention to equity or, possibly, it is the attention to equity that promotes critical thinking and encourages municipalities to choose more complete vulnerability assessment frameworks? The key lesson from this finding, however, is that in order to address equity in adaptation measures, communities must first recognize problems of inequity and injustice in their vulnerability assessment methods. As the baseline for adaptation planning, vulnerability assessment has little value unless it identifies the already existing inequalities and struggles of vulnerable populations. Unless all participants' voices are heard, it is impossible to say whose challenges are represented, how they are conveyed, who benefits from the process, and whether participatory planning is equitable and beneficial for all.

Acknowledgements I would like to thank Professor Charlotte da Cunha of the University of Versailles for fruitful collaboration on methodological frameworks for monitoring local climate adaptation plans discussed in our joint papers cited here. I am also very thankful to the three reviewers, whose insightful comments have helped me to improve the final version of this article. I also want to thank all local planning department officials who kindly responded to my inquiries about the availability of climate adaptation planning documents of their cities and counties. Finally, I am grateful to Grand Valley State University Libraries Open Access Publishing Support Fund for covering the cost of this publication.

Authors' contributions Elena Lioubimtseva is the single author of all materials presented in this manuscript. The author read and approved the final manuscript.

Availability of data and materials The dataset of climate adaptation plans generated and analyzed during this study is fully referenced in Table 1. All 23 climate adaptation plans examined here are publicly available on official websites of their respective municipalities. Quantitative ratings of all assessment criteria of the plans are summarized in Figs. 2, 3, 4 and 5 and are available from the corresponding author upon reasonable request.

\section{Declarations}

Competing interests The author declares no competing interests.

Open Access This article is licensed under a Creative Commons Attribution 4.0 International License, which permits use, sharing, adaptation, distribution and reproduction in any medium or format, as long as you give appropriate credit to the original author(s) and the source, provide a link to the Creative Commons licence, and indicate if changes were made. The images or other third party material in this article are included in the article's Creative Commons licence, unless indicated otherwise in a credit line to the material. If material is not included in the article's Creative Commons licence and your intended use is not permitted by statutory regulation or exceeds the permitted use, you will need to obtain permission directly from the copyright holder. To view a copy of this licence, visit http://creativecommons.org/licenses/by/4.0/.

\section{References}

1. IPCC WGII. Climate Change 2014: Impacts, Adaptation, and Vulnerability, Contribution of Working Group II to the Fifth Assessment Report of the Intergovernmental Panel on Climate Change. IPCC, 2014.

2. Bierbaum R, Smith J, Lee A, Blair M, Carter L, Chapin F, Fleming P, Ruffo S, Stults M, McNeeley S, Wasley E, Verduzco L. A comprehensive review of climate adaptation in the United States: more than before, but less than needed. Mitigat Adapt Strat Global Change. 2013;18:361-406.

3. Woodruff SC, Stults M. Numerous strategies but limited implementation guidance in US local adaptation plans. Nat Clim Chang. $2016 ; 6: 796$.

4. Lioubimtseva E, DaCunha C. Local climate change adaptation plans in the US and France: comparison and lessons learned in $2007-2017$. Urban Clim. 2020;31:10577.

5. Vogel J, Carney KM, Smith JB, Herrick C, Missy S, O'Grady M, St. Juliana A, Hosterman H, Giangola L. Climate adaptation. The state of practice in U.S. communities. The Kresge Foundation and Abt Associates, Detroit; 2016.

6. Olazabal M, Gallaraga I, Ford J, Sainz E, Lesnikowski A. Are local climate adaptation policies credible? A conceptual and operational assessment framework. Int J Urban Sustain Dev. 2019;11(3):277-96.

7. Thomas DS, Twyman C. Equity and justice in climate change adaptation amongst natural-resource-dependent societies. Glob Environ Chang. 2005;15:115-24.

8. International Housing Coalition. Adapting to climate change: cities and the urban poor. Washington, DC: International Housing Coalition; 2011.

9. Reckien D, Lwasa S, Satterthwaite D, McEvoy D, Creutzig F. Equity, environmental justice, and urban climate change. In: Climate Change and Cities: Second Assessment Report of the Urban Climate Change Research Network. New York: Cambridge University Press, 2018; pp. $173-224$. 
10. Anguelovski I, Shi L, Chu E, Gallagher D, Goh K, Lamb Z, Reeve K, Teicher H. Equity impacts of urban land use planning for climate adaptation: critical perspectives from the Global North and South. J Plan Educ Res. 2016;36(3):333-48.

11. Araos M, Berrang-Ford L, Ford JD, Austin SE, Biesbroek R, Lesnikowski A. Climate adaptation planning in large cities: a systematic global assessment. Environ Sci Pol. 2016;66:375-82.

12. Woodruff SC. City membership in climate change adaptation networks. Environ Sci Pol. 2018;84:60-8.

13. James FM, Kwasi AA, Jason-Quashigah P-N, Nagy GJ, Guttierez O, Panario D, Carro I, Sejo L. Challenges to climate change adaptation in coastal small towns: examples from Ghana, Uruguay, Finland, Denmark, and Alaska. Ocean Coast Manage. 2021;105787.

14. Georgetown Climate Center. Adaptation Clearinghouse. 2710 2021. [Online]. Available: https://www.adaptationclearinghouse.org/.

15. da Cunha C, Lioubimtseva E. Metadata for climate change adaptation plans of small and mid-size French and American cities. Data Brief. 2021;106981.

16. Lioubimtseva $E$, da Cunha C. Community engagement and equity in climate adaptation planning: experience of small- and midsized cities in the United States and in France. In: Petersen B, editor. Justice in climate action planning. Strategies for sustainability. Springer: Cham; 2022. p. 257-76.

17. IPCC. Climate Change 2007: impacts, adaptation and vulnerability. Contribution of Working Group II to the Fourth Assessment Report of the Intergovernmental Panel on Climate Change. Cambridge, UK: Cambridge University Press; 2007.

18. Sharma J, Ravindranath N. Applying IPCC 2014 framework for hazard-specific vulnerability assessment under climate change. Environ Res Commun. 2019;051004.

19. Birkmann J, Jamshed A, McMillan JM, Feldmeyer D, Totin E, Solecki W, Zaiton Ibrahim Z, Roberts D, Bezner Kerr R, Poertner H-O, Pelling M, Djalante R, Garschagen M, Filho WL, Guha-Sapir D, Alegría A. Understanding human vulnerability to climate change: a global perspective on index validation for adaptation planning. Sci Tot Environ. 2022;803:150065.

20. Lioubimtseva E. A multi-scale assessment of human vulnerability to climate change in the Aral Sea basin. Environ Earth Sci. 2015;73(2):719-29.

21. Zuniga-Teran AA, Mussetta PC, Lutz Ley AN, Díaz-Caravantes RE, Gerlak AK. Analyzing water policy impacts on vulnerability: cases across the rural-urban continuum in the arid Americas. Environ Dev. 2021;38:100552.

22. Tessema I, Simane B. Vulnerability analysis of smallholder farmers to climate variability and change: an agro-ecological system-based approach in the Fincha'a sub-basin of the upper Blue Nile Basin of Ethiopia. Ecol Process. 2019;8(5):1-18.

23. Inostroza L, Palme M, de la Barrera F. A heat vulnerability index: spatial patterns of exposure, sensitivity, and adaptive capacity of Santiago de Chile. PLoS ONE. 2016;11(19):e0162464.

24. Weis SWM, Agostini VN, Roth LM. Assessing vulnerability: an integrated approach for mapping adaptive capacity, sensitivity, and exposure. Clim Change. 2016;136:615-29.

25. Swami D, Parthasarathy D. Dynamics of exposure, sensitivity, adaptive capacity and agricultural vulnerability at district scale for Maharashtra, India. Ecol Indicat. 2021;121:107206.

26. Howe PD, Yarnal B, Coletti A, Wood NJ. The participatory vulnerability scoping diagram-deliberative risk ranking for community water systems. Ann Assoc Am Geogr. 2013;2(103):343-52.

27. Polsky C, Neff R, Yarnal B. Building comparable global change vulnerability assessment: the vulnerability scoping diagram. Glob Environ Chang. 2007;17(3):472-85.

28. Coletti A, Howe PD, Yarnal B, Wood NJ. Nat Hazards. 2013;65(1): 10.

29. Monterroso A, Conde C. Exposure to climate and climate change in Mexico, Geomatics. Nat Hazards Risks. 2015;6(4):272-88.

30. Brown A, Gawith M, Lonsdale K, Pringle P. Managing adaptation: linking theory and practice. School of Geography and the Environment: University of Oxford, Oxford, UK; 2011.

31. ICLEI Local Governments for Sustainability. Changing Climate, Changing Communities Guide and Workbook for Municipal Climate Adaptation. ICLEI-Canada, Toronto, ON, 2019.

32. Smit B, Wandel J. Adaptation, adaptive capacity and vulnerability. Glob Environ Chang. 2006;16:282-92.

33. Duncan LA, Schaller M, Park JH. Perceived vulnerability to disease: development and validation. Personality Individ Differ. 2009;47:541-6

34. Weinstein ND, Lyon JE, Rothman AJ, Cuite CL. Changes in pereceived vulnerability following natural disaster. J Soc Clin Psychol. 2000;19(3):372-95

35. Gerard M, Gibbons FX, Bushman BJ. Relation between perceived vulnerability to HIV and precautionary sexual behavior. Psychol Bull. 1996;119(3):390-409.

36. Shi L, Chu E, Anguelovski I, Aylett A, Debats J, Goh K, Schenk T, Seto KC, Dodman D, Roberts D, Timmons JR, VanDeever SD. Roadmap towards justice in urban climate adaptation research. Nat Clim Chang. 2016;6:131-7.

37. United Nations. UN Sustainable Development Goals. 16 October 2021. [Online]. Available: https://www.un.org/sustainabledevelopme nt/blog/2019/05/climate-justice/.

38. Bulkeley H, Carmin J, CastanBroto V, Edwards GA, Fuller S. Climate justice and global cities: mapping the emerging discourses. Glob Environ Change. 2013;23(5):914-25.

39. Northridge M, Freeman L. Urban planning and health equity. J Urban Health. 2011;88(3):582-97.

40. Roberson QM. Disentangling the meanings of diversity and inclusion. Center for Advanced Human Resource Studies/Cornell University Working Paper Series, Vols. CAHRS WP 04-05, pp. 2-31, June 2004.

41. Agyeman J, Bullard R, Evans BE. Just sustainabilities: development in an unequal world. Cambridge, MA: MIT Press; 2003.

42. Miranda M, Edwards S, Keating M, Paul C. Making the environmental justice grade: the relative burden of air pollution exposure in the United States. Int J Environ Res Public Health. 2011;8(6):1755-71.

43. Andersson E, Lngemeyer J, Borgström S, McPhearson T, Haase D, Kronenberg J, Brton DN, Davis M, Naumann S, Röschel L, Baró F. Enabling green and blue infrastructure to improve contributions to human well-being and equity in urban systems. Bioscience. 2019;69(7):566-74.

44. Shore LM, Randel AE, Chung BG, Dean MA, Holcombe Ehrhart K, Singh G. Inclusion and diversity in work groups. J Manage. 2011;37(4):1262-89. 
45. Uittenbroek C, Mees H, Hegger D, Driesses P. The design of public participation: who participates, when and how? Insights in climate adaptation planning from the Netherlands. J Environ Planning Manage. 2019;62(14):2529-47.

46. Holland B. Procedural justice in local climate adaptation: political capabilities and transformational change. Environ Polit. 2017;26(3):391-412.

47. International Association for Public Participation. IAP2 Spectrum of Public Participation. 2018. [Online]. Available: https://cdn.ymaws. com/www.iap2.org/resource/resmgr/pillars/Spectrum_8.5x11_Print.pdf. [Accessed 2021].

48. California Governor's Office of Emergency Services. California Adaptation PLanning Guide. Governor's Office of Emergency Services, Sacramento, CA, 2020.

49. Institute for Local Government. Climate Adaptation and Resilience. 2610 2021. [Online]. Available: https://www.ca-ilg.org/.

50. Model Forestry Policy Program. Climate Solutions University. 0810 2021. [Online]. Available: https://www.mfpp.org/climate-solutionsuniversity-2/.

51. Lioubimtseva $E$, da Cunha C. Community engagement and equity in climate adaptation planning: experience of small- and mid-sized cities in the United States and in France. In: Peterson B, Ducros H, editors. Justice in climate action planning. Cham: Springer International Publishing; 2022.

52. Michigan State University. Adapting to Climate Change and Variability. Marquette, Michigan. Michigan State University, City of Marquette, Superior Watershed Partnership and Land Trust, Marquette, MI, 2013.

53. King H, Thaler T, Griffith G, Crossett T, Rasker R. Forest and water climate adaptation: a plan for Marquette County, Michigan. Model Forest Policy Program, Sagle, ID, 2013.

54. Rivas S, Hernandez Y, Urraca R, Barbosa P. A comparative analysis to depict underlying attributes that might determine the successful implementation of local adaptation plans. Environ Sci Policy. 2021;7:25-33.

55. Aguiar FC, Bentz J, Silva JM, Fonseca AL, Swart R, Santos FD, Penha-Lopes G. Adaptation to climate change at local level in Europe: an overview. Environ Sci Policy. 2018;86:38-63.

56. Elelman R, Feldman DL. The future of citizen engagement in cities - the council of citizen engagement in sustainable urban strategies (ConCensus). Futures. 2018;101:80-91.

57. Hügel S, Davies AR. Public participation, engagement, and climate change adaptation: a review of the research literature. WIREs Clim Change. 2020;11(4):1-20.

58. California Natural Resources Agency \& the Governor's Office of Planning and Research. 2021 California Climate Adaptation Strategy. State of California, Sacramento, 2021.

59. California Environmental Protection Agency. California Environmental Protection Agency. 2710 2021. [Online]. Available: https://calepa. ca.gov/.

60. Geospatial Innovation Facility at University of California. Cal-Adapt. 2710 2021. [Online]. Available: https://cal-adapt.org/.

61. City of Laguna Woods City Council. City of Laguna Woods Climate Adaptation Plan. City of Laguna Woods, Laguna Woods, CA, 2014.

62. City of Santa Cruz Climate Action Program. City of Santa Cruz 2018 Climate Adaptation Plan Update. City of Santa Cruz, Santa Cruz, CA, 2018.

63. Town of Corte Madera. Town of Corte Madera Climate Adaptation Assessment: A Roadmap to Resilience. Town of Corte Madera, Corte Madera, CA, 2021.

64. Harris and Associates. City of Watsonville Climate Action and Adaptation Plan. City of Watsonville Public Works \& Utilities, Watsonville, CA, 2021.

65. New York State Department of State. Albany Climate Change Vulnerability Assessment and Adaptation Plan. Mayor's Office of Energy and Sustainability, Albany, NY, 2013.

66. Georgetown Conservation Commission. Climate Change Adaptation Report: Georgetown, Maine. A special publication by the Georgetown Conservation Commission. Georgetown Conservation Commission, Georgetown, ME, 2015.

67. Evans J, Gambill J, McDowell R. Tybee Island Sea Level Rise Adaptation Plan. Final Report. National Sea Grant College Program, Tybee Island, GA, 2013.

68. Klipp J, Thaler T, Griffith G, Crossett T. Climate Adaptation and Mitigation Plan for Alger County, Michigan. Preparing Communities, Forests and Water Resources for a Changing Climate. Model Forest Policy Program, Sagle, ID, 2011.

69. Stratus Consulting. Boulder County Climate Change. Boulder County, Boulder County, CO, 2012.

70. City of Chula Vista. Climate Adaptation Strategies Final Implementation Plans. City of Chula Vista, Chula Vista, CA, 2011.

71. City of Flagstaff. City of Flagstaff Resiliency and Preparedness Study. City of Flagstaff, Flafstaff, AZ, 2012.

72. City of Flagstaff. Flagstaff Climate Action and Adaptation Plan. City of Flagstaff, Flagstaff, 2018, 2018.

73. Stults M, Pagach J. Preparing for Climate Change in Groton, Connecticut: A Model Process for Communities in the Northeast. ICLEI-Local Governments for Sustainability and Connecticut Department of Environmental Protection, Groton, CT, 2011.

74. City of lowa City. lowa City Climate Action and Adaptation Plan. City of lowa City, lowa City, IA, 2018.

75. City of Keene. Adapting to Climate Change: Planning a Climate Resilient Community. City of Keene \& ICLEl Local Governments for Sustainability, Keene, $\mathrm{NH}, 2007$.

76. City of Keene. Keene, NH Climate Adaptation Action Plan Final Report. City of Keene \& ICLEl Local Governments for Sustainability, Keene, $\mathrm{NH}, 2010$.

77. Chase JH, Cooper JG, Fitzgerald RE, Lima FA, Miller SR, Pignatelli TM. Climate Change Adaptation Chapter: Marshfield, Massachusetts. ScholarWorks@UMass Amherst, Amherst, MA, 2012.

78. Rhode Island Sea Grant \& University of Rhode Island Coastal Resources Center. Adaptation to Natural Hazards and Climate Change in North Kingstown, Rhode Island. Rhode Island Statewide Planning Program, Providence, RI, 2015.

79. Beever JIII, Gray W, Trescott D, Cobb D, Utley J, Hutchinson D. City of Punta Gorda Adaptation Plan. Southwest Florida Regional Planning Council, Charlotte Harbor National Estuary Program, Fort Myers, FL, 2009.

80. I. Taylor Engineering. City of Punta Gorda Adaptation Plan Update. City of Punta Gorda, Punta Gorda, FL, 2019.

81. City of Salem Department of Planning \& Community Development. Ready for Tomorrow: The City of Salem Climate Change Vulnerability Assessment and Adaptation Plan. City of Salem, Salem, MA, 2014. 
82. City of Santa Cruz. City of Santa Cruz Climate Adaptation Plan. City of Santa Cruz, Santa Cruz, CA, 2011.

83. City of Sarasota. City of Sarasota Climate Change Vulnerability and Adaptation Plan. Technical Memo. City of Sarasota, Sarasota, FL, 2016.

84. City of Sarasota. City of Sarasota Climate Adaptation PLan. Final Report. City of Sarasota, Sarasota, FL, 2017.

85. Foster M, Williams R, Thaler T, Griffith G. Forest and water climate adaptation: a plan for Taos County, New Mexico. Model Forest Policy Program, Sagle, ID, 2010

86. Tompkins County Planning Department. Tompkins County Comprehensive Plan. Planning for Our Future: Adaptation Chapter. Tompkins County, Ithaca, NY, 2015.

Publisher's Note Springer Nature remains neutral with regard to jurisdictional claims in published maps and institutional affiliations. 